\title{
CONSTRUCTAL DESIGN APPLIED TO A FINNED CHANNEL UNDER FORCED CONVECTION FLOWS WITH DIFFERENT IMPOSED PRESSURE DROPS
}

\author{
B. C. Feijó ${ }^{a}$, \\ F. B. Teixeira ${ }^{a}$, \\ M. S. Pereira ${ }^{a}$, \\ L. A. O. Rocha ${ }^{b}$, \\ J. N. V. Goulart ${ }^{\mathrm{c}}$, \\ L. A. Isoldi ${ }^{\mathrm{a}}$, \\ and E. D. Santos ${ }^{\mathrm{a}}$ \\ bruno.feijo1989@gmail.com \\ Porto Alegre, RS, Brasil
}

${ }^{\text {a } U n i v e r s i d a d e ~ F e d e r a l ~ d o ~ R i o ~ G r a n d e ~}$

Programa de Pós-Graduação em Eng. Oceânica

Av.Itália, km 8, Rio Grande, RS, Brasil

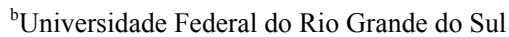

Departamento de Engenharia Mecânica

Rua Sarmento Leite, 425, CEP 90050-170

${ }^{c}$ Universidade de Brasília, Grupo de Mecânica

Experimental e Computacional, Gama, DF,

CEP 72.405-610, CP 8114, Brasil.

Received: May 11, 2017

Revised: June 12, 2017

Accepted: July 12, 2017

\section{ABSTRACT}

This paper aims to numerically study the heat transfer in a two dimensional finned channel under laminar, incompressible and forced convective flow with adiabatic walls. The main purpose is to maximize the convection heat transfer by changing the fin's dimensions by means of Constructal Design. Numerical computations are performed for different Bejan numbers ranging from 0.182 up to 18.2. For all simulations the Prandlt number is kept constant, $\operatorname{Pr}=0.71$. The fluid motion throughout the channel is caused by imposition of pressure difference between inlet/outlet surfaces. Concerning heat transfer, it is caused by the difference of temperature between the inlet stream of fluid and the heated fins placed at the channel surfaces. The first fin is positioned in the lower surface of the channel while the second one is placed in the upper one. The problem is submitted to three constraints, the channel area $(\mathrm{H} \times \mathrm{L})$, area of two fins and occupancy areas for the fins. It is considered here that both fins have the same fraction area (ratio between the fins and occupancy areas) $\phi=0.2$. The problem is submitted to three degrees of freedom: $\mathrm{H} / \mathrm{L}$ (ratio between height and length of channel), $\mathrm{H}_{3} / \mathrm{L}_{3}$ and $\mathrm{H}_{4} / \mathrm{L}_{4}$ which represent the ratio between the height and length of the first and second fin, respectively. Here, the second fin remains unchanged, being its dimensions $\mathrm{H}_{4} / \mathrm{L}_{4}=2.0$, whereas the first one is free to modify its dimensions, $\mathrm{H}_{3} / \mathrm{L}_{3}$. The channel dimensions are also constant. The solutions are sought using the conservation equations of mass, momentum and energy being these ones discretized through the Finite Volume Method (FVM). Results showed the importance of Constructal Design application for thermal improvement of the problem. Thermal efficiency differences of 5 times where achieved when comparing the best and worst cases. Other important observation is concerned with the effect of ratio $\mathrm{H}_{3} / \mathrm{L}_{3}$ over heat transfer ratio $(q)$ which varied significantly from a case where a pressure drop is imposed in the channel to other case where the driven force is caused by imposition of velocity field at the channel inlet.

Keywords: numerical simulation, constructal design, finned channel, forced convection, Bejan number

\section{NOMENCLATURE}

$\mathrm{A}_{1} \quad$ fin's occupancy area, $\mathrm{m}^{2}$

$\mathrm{A}_{2} \quad$ fin's area, $\mathrm{m}^{2}$

Be Bejan number, $\Delta \mathrm{PL}^{2} / \mu \alpha$

$\mathrm{c}_{\mathrm{p}} \quad$ specific heat, $\mathrm{J} /(\mathrm{Kg} . \mathrm{K})$

$\mathrm{H}$ channel's height, $\mathrm{m}$

$\mathrm{H}_{3}, \mathrm{H}_{4}$ fin's height, $\mathrm{m}$

$\mathrm{k}$ thermal conductivity, $\mathrm{W} /(\mathrm{m} . \mathrm{K})$

L channel's length, $m$

$\mathrm{L}_{1}, \mathrm{~L}_{2}$ fin's occupancy area length, $\mathrm{m}$

$\mathrm{L}_{3}, \mathrm{~L}_{4}$ fin's length, $\mathrm{m}$

$\mathrm{p}$ pressure, $\mathrm{Pa}$

Pr Prandlt number, $v / \alpha$

$\mathrm{q}$ heat transfer rate, $\mathrm{W}$

$\mathrm{Re}_{\mathrm{H}} \quad$ Reynolds number, $\rho \mathrm{H} / \mu$

$\mathrm{T}$ temperature, $\mathrm{K}$

$\mathrm{u}, \mathrm{v}$ stream, spanwise velocity components, $\mathrm{m} / \mathrm{s}$

$\mathrm{x}, \mathrm{y}$ cartesian coordinates, $\mathrm{m}$

\section{Greek symbols}

a thermal diffusivity, $\mathrm{m}^{2} / \mathrm{s}$

$\rho$ density, $\left(\mathrm{kg} / \mathrm{m}^{3}\right)$

$v \quad$ kinematic viscosity, $\mathrm{m}^{2} / \mathrm{s}$

$\mu \quad$ dynamic viscosity, $\mathrm{Kg} /(\mathrm{m} . \mathrm{s})$

\section{Superscripts \\ $\mathrm{f}$ final \\ J current}

\section{Subscripts}

Fin fin

$\mathrm{m} \quad$ once maximized

max maximum

o once optimized

w wall 


\section{INTRODUCTION}

Internal flow in finned channels and tubes are subject of research interest in engineering mainly because of the heat transfer enhancement due to the fins. The knowledge of the features of the flow inside this kind of channels and how it has been coupling with the heat transfer processes is crucial for many branches of engineering that seek high thermal performance as heat exchangers, thermal machines and electronic devices as well. The performance enhancement is sought through the maximization of the convection heat transfer coefficient in cases in which the forced convection dominates the heat transfer process. Therefore, the optimization techniques applied to such cases can lead to good result. In these cases, the optimization can be aimed to target either the geometry or the geometric parameter of system in order to maximize or minimize a chosen process. In heat transfer processes the current optimization tools are very suitable to apply in parallel with computational codes, avoiding excessive computational costs or even the costs associated to an experimental campaign.

In this work Constructal Design is used to maximize the heat transfer process in a finned channel. This method is based on the Constructal Law which is a physical principle that states that for a given flow system to remain alive along the time its configuration must evolve in such way that maximizes its internal currents (Bejan, 2000; Bejan e Lorente, 2008, Bejan e Zane, 2012). Constructal Design uses the method of objective and restrictions to evaluate the effect of geometry or parameters over one or more objectives aiming to minimize the system imperfections. According to Rocha et al. (2005) best geometries are mostly sough in problems involving heat transfer, fluid dynamics, optimization in cavities or finned tubes.

Works based on the Constructal Design were published by Rocha et al. (2005); Kundu and Bhanja (2010); Lorenzini et al. (2011a) among others. The authors above carried out numerical simulations on the heat transfer processes in cavities and fins, for different shapes $(\mathrm{C}, \mathrm{Y}$ and $\mathrm{T})$. Furthermore, finned cavities were also studied by using the same technique (Lorenzini et al, 2011b; Lorenzini et al, 2012).

Important works of Bejan and Lorente (2008, 2011, 2013) and Reis (2006) showed that Constructal Design is not only a method for engineering evaluation, but a method used to view the design and evolution in physics, biology, technology and social sciences. Into heat exchangers realm, Fan and Luo (2008) promoted contributions to rise knowledge on the Constructal Design applied to heat exchangers. Afterwards, Azad and Amidpour (2011) showed that the Constructal Design may successfully applied to shell-tubes heat exchangers. The authors also pointed that the cost involved in the project may be reduced at least $50 \%$ in comparison with traditional methods used to set up shell-tube heat exchangers.

This paper aims to maximize the heat flux in a rectangular channel containing two rectangular fins for three different Bejan numbers, $\mathrm{Be}=0.182,1.82$ and18.28, by means of Constructal Design associated with exhaustive search. In other words, Constructal Design is used to define the search space and all possibilities are simulated (with exhaustive search). The flow inside the finned channel is laminar and the Prandlt number is kept constant during the simulations, $\operatorname{Pr}=0.71$. The fin's geometry are height, $\mathrm{H}_{3}$ and $\mathrm{H}_{4}$, and length, $\mathrm{L}_{3}$ and $\mathrm{L}_{4}$, confined in a space with height $\mathrm{H}$, and lengths $\mathrm{L}_{1}$ and $\mathrm{L}_{2}$. The geometry is subjected to three restrictions: 1) total area of the fins, 2) area of occupancy of the fins, 3) total area of the channel. The system has three degrees of freedom given by the ratio between height and length of the channel, which is kept fixed, $\mathrm{H} / \mathrm{L}=$ 0.0625 , the ratio between height and the length of the first fin $\left(\mathrm{H}_{3} / \mathrm{L}_{3}\right)$, which is located on the lower wall of the channel, and the ratio between height and length of the second fin $\left(\mathrm{H}_{4} / \mathrm{L}_{4}\right)$, located on the upper wall of the channel, which is also kept fixed, $\mathrm{H}_{4} / \mathrm{L}_{4}=2.0$. To perform calculations the discretization is performed with the Finite Volume Method (FVM), more precisely employing the commercial code FLUENT ${ }^{\circledR}$ (Patankar, 1980; Versteeg and Malalasekera, 2007; FLUENT, 2007).

\section{PROBLEM DESCRIPTION}

The physical problem analyzed consists of a two dimensional channel with two fins, as shown in Fig. 1. The fluid used in the study is air and its movement is generated by imposing a pressure at the channel's inlet, on the left, and also at the channel's outlet, on the right. In this study the channel area $(\mathrm{A}=\mathrm{H} . \mathrm{L}=$ $2500 \mathrm{~mm}^{2}$ ) and the ratio between the area of the fins over its occupancy area $\left(\phi=\phi_{1}=\phi_{2}=0.2\right)$ will be kept fixed. The ratio between the height and the length of the first fin $\left(\mathrm{H}_{3} / \mathrm{L}_{3}\right)$ will be varied. A channel with a length of $\mathrm{L}=800 \mathrm{~mm}$ and height $\mathrm{H}=$ $50 \mathrm{~mm}$ was considered. The degrees of freedom are optimized for a laminar flow with Prandtl number of $\operatorname{Pr}=0.71$ and a prescribed temperature $\left(\mathrm{T}_{\infty}=300 \mathrm{~K}\right)$ at the inlet of the channel. The manometric pressure at the outlet is considered $\mathrm{P}_{\text {out }}=0 \mathrm{~Pa}$. At the walls, no-slip condition is applied. Boundary conditions for heat problem were also imposed. The channel's walls are adiabatic and prescribed temperature, $\mathrm{T}_{\mathrm{w}}=330 \mathrm{~K}$, is imposed at the fin's walls. Based on the pressure difference, the total length of the channel, L, the thermal diffusivity, $\alpha$ and the viscosity, $\mu$, three different Bejan numbers were simulated, $\mathrm{Be}=0.182$, 1.82 and 18.28, for convection heat transfer assessment.

The problem optimization is bounded by three different regions, the channel area, $(\mathrm{A})$, the fins occupancy area $\left(\mathrm{A}_{1}\right)$ and the area of the fins itself 
$\left(A_{2}\right)$. The equations for area of geometries are given by:

$$
\begin{gathered}
A=H \times L \\
A_{1}=H \times L_{1}=H \times L_{2} \\
A_{2}=H_{3} \times L_{3}=H_{4} \times L_{4}
\end{gathered}
$$

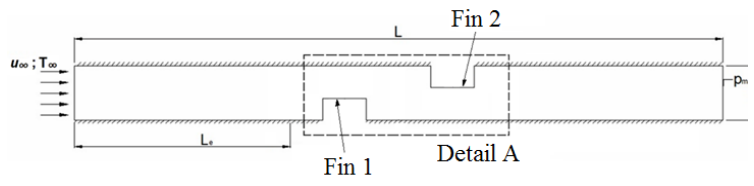

Detail A:

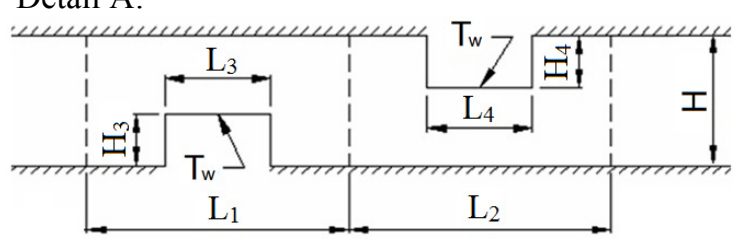

Figure 1. Computational Domain of the finned channel.

The Bejan number, Be, is widely employed in heat transfer problems to represent dimensionless pressure drop along the channel's length, L. According to Bejan is a good tool to compare different flow that the pressure gradient is the dominant force. Bejan number is given by (Bejan, 2014):

$$
B e=\frac{\Delta P L^{2}}{\mu \alpha}
$$

where $\Delta \mathrm{P}$ is the pressure difference between inlet and the channel's outlet (Pa), $\mathrm{L}$ is total length of the channel (m), $\mu$ is the dynamic viscosity $(\mathrm{kg} / \mathrm{m} . \mathrm{s})$ and $\alpha$ is thermal diffusivity of the fluid $\left(\mathrm{m}^{2} / \mathrm{s}\right)$.

The optimization process was carried out as stressed in Fig. 2. Firstly, the geometry is optimized through the $\mathrm{H}_{3} / \mathrm{L}_{3}$ - ratio variation. This geometric parameter is free to change from 0.25 up to 4.0 , for a constant $\mathrm{Be}=1.82$.

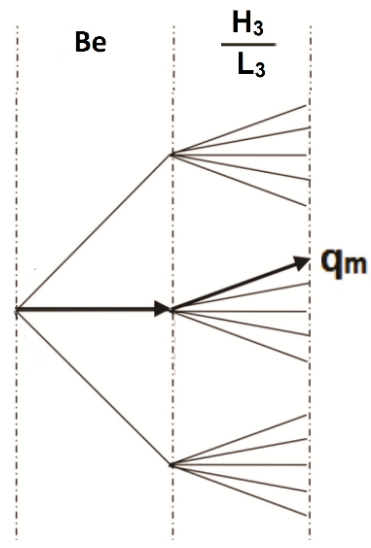

Figure 2. Sketch of the optimization process applied to a finned channel.

During the calculations the once maximized heat transfer rate value is achieved, $\mathrm{q}_{\mathrm{m}}$, and the corresponding geometry is the once optimized ratio $\mathrm{H}_{3} / \mathrm{L}_{3}$, $\left(\mathrm{H}_{3} / \mathrm{L}_{3}\right)_{0}$. Afterwards, the processes is then repeated for each Bejan numbers $(\mathrm{Be}=0.182,1.82$ and 18.28) to assess the influence of Bejan number over $\mathrm{q}_{\mathrm{m}}$ and $\left(\mathrm{H}_{3} / \mathrm{L}_{3}\right)_{\mathrm{o}}$. Figure 2 shows a sketch of the optimization process where 48 simulations are performed.

\section{MATHEMATICAL MODELING NUMERICAL PROCEDURE}

For laminar, incompressible steady state forced convective flows the mass, momentum in $\mathrm{x}$ and $\mathrm{y}$ directions and energy conservation equations are given by (Bejan, 2014):

$$
\frac{\partial u}{\partial x}+\frac{\partial v}{\partial y}=0
$$

$$
\begin{gathered}
u \frac{\partial u}{\partial x}+v \frac{\partial u}{\partial y}=-\frac{1}{\rho} \frac{\partial \rho}{\partial x}+v\left(\frac{\partial^{2} u}{\partial x^{2}}+\frac{\partial^{2} u}{\partial y^{2}}\right) \\
u \frac{\partial v}{\partial x}+v \frac{\partial v}{\partial y}=-\frac{1}{\rho} \frac{\partial \rho}{\partial y}+v\left(\frac{\partial^{2} v}{\partial x^{2}}+\frac{\partial^{2} v}{\partial y^{2}}\right) \\
u \frac{\partial T}{\partial x}+v \frac{\partial T}{\partial y}=\frac{k}{\rho c_{p}}\left(\frac{\partial^{2} T}{\partial x^{2}}+\frac{\partial^{2} T}{\partial y^{2}}\right)
\end{gathered}
$$

$u$ and $\mathrm{v}$ are the stream spanwise velocity components, $(\mathrm{m} / \mathrm{s}) ; \mathrm{p}$ is the pressure $(\mathrm{Pa}), v$ is the kinematic viscosity $\left(\mathrm{m}^{2} / \mathrm{s}\right), \rho$ is the air density $\left(\mathrm{kg} / \mathrm{m}^{3}\right)$, $\mathrm{T}$ is the temperature $(\mathrm{K}), \mathrm{c}_{\mathrm{p}}$ and $\mathrm{k}$ are the specific heat and the thermal conductivity, (J/kg.K) and (W/m.K), respectively.

The scheme employed to solve Eqs. (1) - (3) is based on the pressure. For the advection terms it is used second order Upwind scheme. Pressure velocity coupling is done by using SIMPLEC method (Versteeg and Malalasekera, 2007). Furthermore, sub-relaxation factors 1.0, 0.6 and 0.8 were imposed to the equations for mass, momentum and energy, respectively. The maximum numeric residue was imposed to be $10^{-6}, 10^{-6}$ and $10^{-8}$, for mass, momentum and energy equations, respectively.

The mesh is built employing the commercial software GAMBIT, with 26,000 finite volumes, as shown in Fig. 3.

The numerical simulations are carried out in a computer Intel i5 $3.10 \mathrm{GHz}$ and $8 \mathrm{~GB}$ RAM. Each optimization took about 5 up to $15 \mathrm{~min}$ to get ready. 

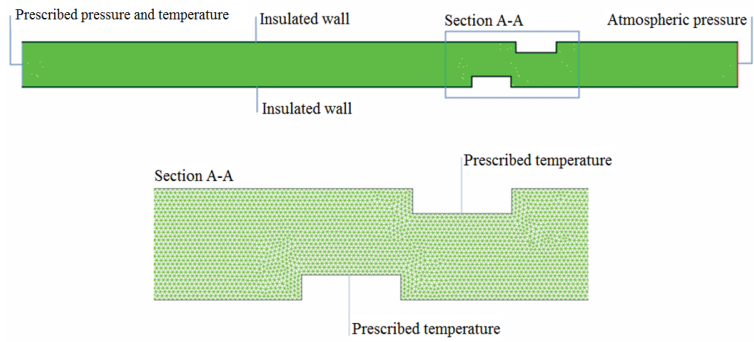

Figure 3. Spatial discretization applied to the finned channel.

To verify the quality of the mesh refinement, a mesh independence test was performed. As a comparison value, the total heat transfer rate (q) of the two fins was chosen. It was considered that a mesh with 25,826 finite volumes satisfies the needs of this work. According to the results obtained, the following value was obtained as acceptance criterion:

$$
\left|\left(q_{\text {max }}^{\mathrm{j}}-\mathrm{q}^{\mathrm{j}+{ }_{\text {max }}}\right) / \mathrm{q}_{\text {max }}^{\mathrm{j}}\right|<1.1 \times 10^{-6}
$$

\section{RESULTS AND DISCUSSION}

As previously mentioned in this work, 16 cases were simulated for each of the three Bejan numbers under study, varying the ratio $\mathrm{H}_{3} / \mathrm{L}_{3}$ between the range of 0.25 and 4.0 , in order to determine the geometry with the best thermal performance. The results obtained can be seen in Fig. 4. The highest values for the heat transfer rate $(q)$ were obtained for $\mathrm{Be}=18.28$ while the lowest values of $(q)$ were obtained for $\mathrm{Be}=0.182$, as expected, since the increase in the Bejan number represents an increase in the driving force of the flow. It is also noticed that for all evaluated $\mathrm{Be}$, the lowest ratio of $\mathrm{H}_{3} / \mathrm{L}_{3}$ conducted to the best thermal performance, contrarily to previous observations where the velocity is imposed at the inlet of domain. In Figure 5 we can observe the temperature fields for the optimal geometries, $\left(\mathrm{H}_{3} / \mathrm{L}_{3}\right)_{0}$, for the three values of $(\mathrm{Be})$. A higher value for $(\mathrm{Be})$ means a higher pressure drop between the inlet and outlet of the channel, which causes a higher flow velocity and consequently a higher heat transfer between the heated walls and the fluid. Figure 6 shows the velocity fields for the optimal geometries and provide help in a better understanding of this phenomenon.

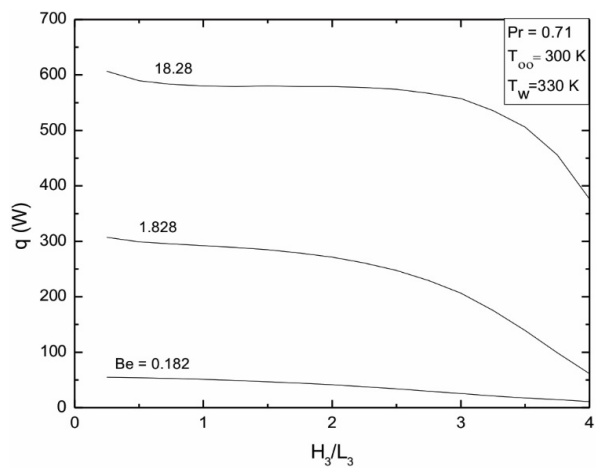

Figure 4. Effect of $\mathrm{H}_{3} / \mathrm{L}_{3}$ on the heat transfer rate (q) for different Bejan numbers $(\mathrm{Be})$.

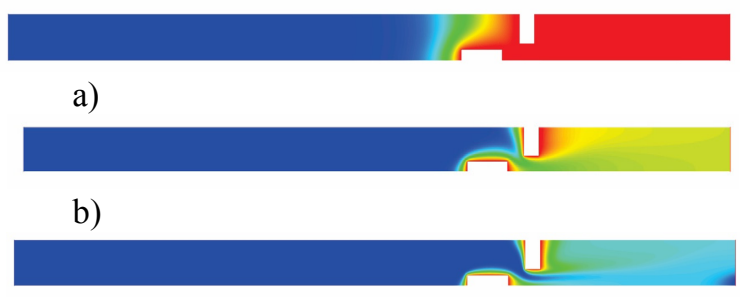

c)

Figure 5. Temperature fields for the geometries with the best thermal performance: a) $\mathrm{Be}=0.182$, b) $\mathrm{Be}=$ $1.828, \mathrm{c}) \mathrm{Be}=18.28$.

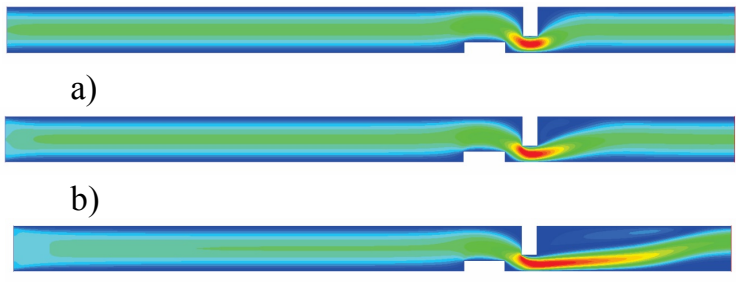

c)

Figure 6. Velocity fields for the geometries with best thermal performance: a) $\mathrm{Be}=0.182$, b) $\mathrm{Be}=1.828$, c) $\mathrm{Be}=18.28$.

Figure 7 shows how much each fin (fin 1 for the lower-wall fin and fin 2 for the upper-wall fin) contributes to the total heat transfer, along the range of $\mathrm{H}_{3} / \mathrm{L}_{3}$ under study. Note that for the smallest value of $\mathrm{Be}(0.182)$ the contribution of the upper-wall fin is much smaller. The reason for such an event is that for this Bejan number, the flow's velocity is considerably smaller compared to the other two values of $(\mathrm{Be})$, which causes the cooler fluid to pass through the first fin and to heat up almost completely to the fin's wall temperature from this point, as can be seen in Fig. 5 (a). This fact does not occur for the higher values of (Be) because the higher flow's velocity causes it not to be able to completely heat up to the fin's wall temperature when passing through the first fin. The best shapes reached in Fig. 1 are compiled and presented in Figs. 8 and 9. More precisely, Figs. 8 and 9 depict the effect of $\mathrm{Be}$ over the once maximized heat transfer rate $\left(\mathrm{q}_{\mathrm{m}}\right)$ and the once optimized ratio of $\mathrm{H}_{3} / \mathrm{L}_{3},\left(\mathrm{H}_{3} / \mathrm{L}_{3}\right)_{0}$. It can be noticed that the optimal shape was the same for all evaluated Be numbers.

In this work, a difference of pressure between the entrance and exit of the channel was imposed. Figure 10 shows the same problem but now simulated with a velocity field imposed at the channel's entrance with a Reynolds number of $\mathrm{Re}_{\mathrm{H}}=100$. It is possible to note that the main difference is concerned with the effect of the ratio $\mathrm{H}_{3} / \mathrm{L}_{3}$ over $\mathrm{q}$, including the optimal shape achieved. For this case, unlike the previous one where a pressure drop was imposed, 
there is a tendency of increasing of the heat exchange with the increase of $\mathrm{H}_{3} / \mathrm{L}_{3}$. This fact can be understood by re-analyzing the case with a pressure difference imposed with the aid of Fig. 11 which shows the temperature and velocity fields for the geometry with the worst thermal performance for Be $=1.828$. Comparing Fig. 11 to Fig. 6, it can be noted that increasing the height of the first fin causes a larger decrease in fluid velocity as it passes through the first fin due to increased flow obstruction, greatly reducing the thermal exchange of the second fin (the first fin also has a drop in the thermal exchange with the increase of the fin's height but that happens in a smaller rate, as shown in Fig. 7). This does not occur when there is a prescribed velocity at the entrance of the channel. In this case, the fluid is able to maintain a higher velocity when passing through the fins, even in the case where the height of the fins is close to the maximum, as can be seen in Fig. 12. Thus, in the case where $\mathrm{Re}_{\mathrm{H}}$ is imposed it is necessary to evaluate the problem considering two objectives (heat transfer rate and the channel pressure drop).

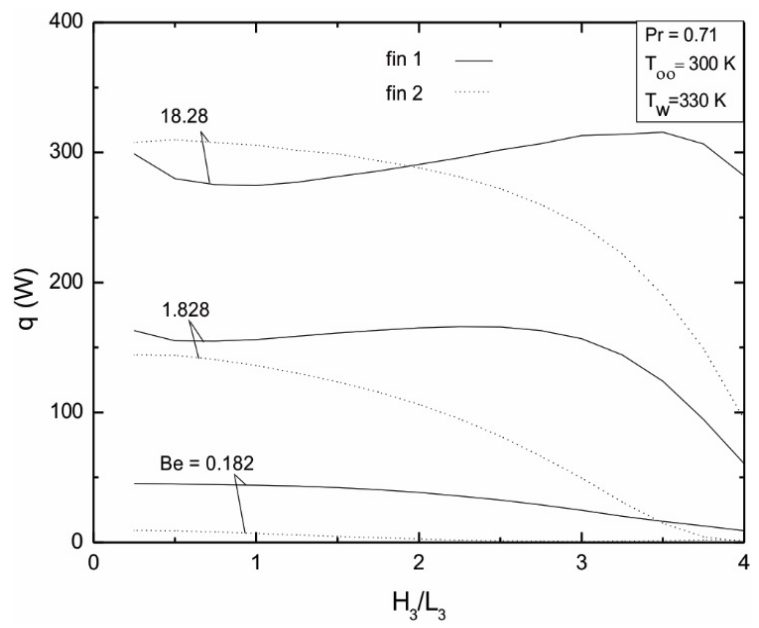

Figure 7. Effect of $\mathrm{H}_{3} / \mathrm{L}_{3}$ on heat transfer rate (q) per fin for different Bejan numbers $(\mathrm{Be})$.

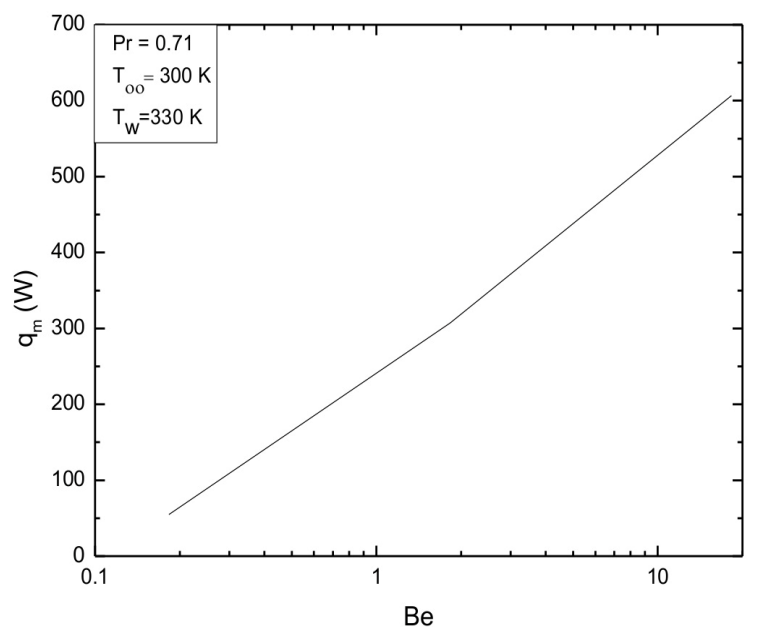

Figure 8. Effect of the Bejan number $(\mathrm{Be})$ on the rate of the once maximized heat transfer $\left(\mathrm{q}_{\mathrm{m}}\right)$.

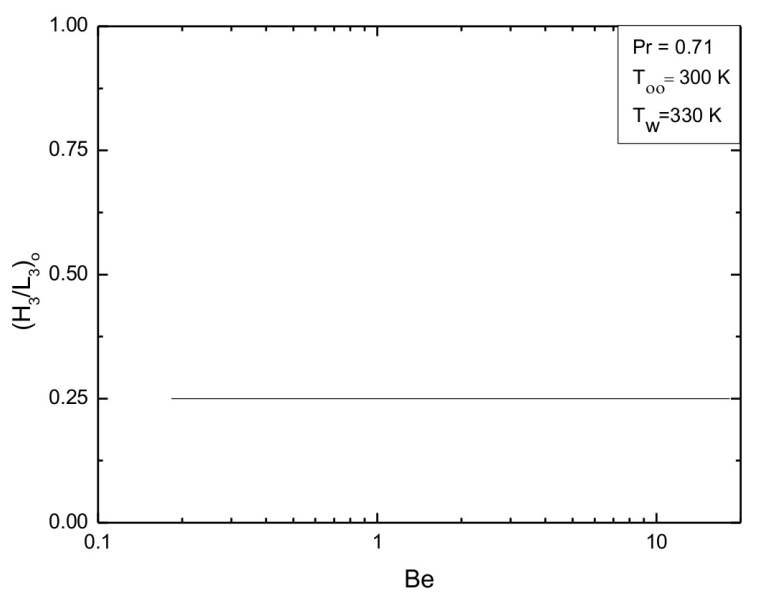

Figure 9. Effect of the Bejan number $(\mathrm{Be})$ on the ratio $\left(\mathrm{H}_{3} / \mathrm{L}_{3}\right)_{\mathrm{o}}$.

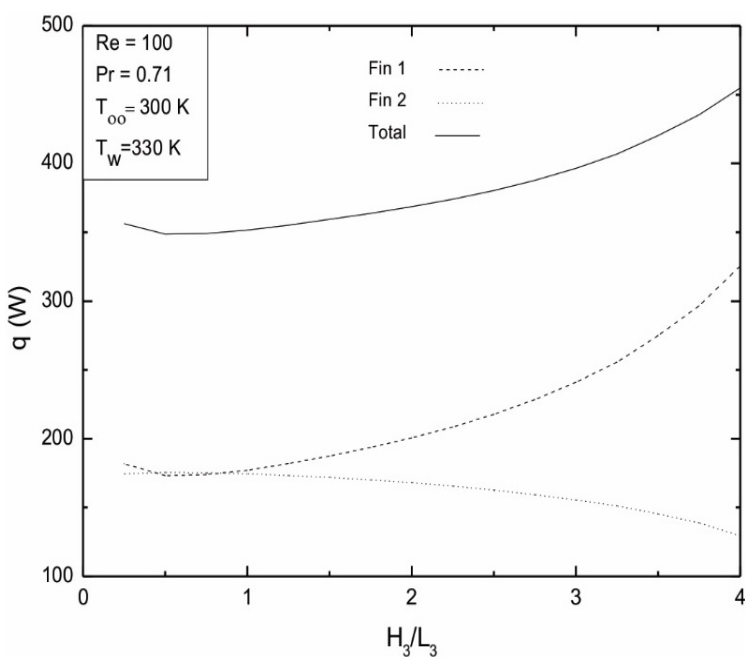

Figure 10. Effect of $\mathrm{H}_{3} / \mathrm{L}_{3}$ on heat transfer rate (q) for Reynolds number $\mathrm{Re}_{\mathrm{H}}=100$.

a)

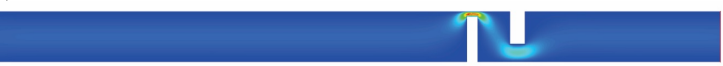

b)

Figure 11. a) Temperature field for $\mathrm{Be}=1.828$ and $\mathrm{H}_{3} / \mathrm{L}_{3}=4.0$, b) Velocity field for $\mathrm{Be}=1.828$ and $\mathrm{H}_{3} / \mathrm{L}_{3}=4.0$.

a)

b)

Figure 12. a) Temperature field for $\mathrm{Re}_{\mathrm{H}}=100$ and $\left.\mathrm{H}_{3} / \mathrm{L}_{3}=4.0, \mathrm{~b}\right)$ Velocity field for $\mathrm{Re}_{\mathrm{H}}=100$ and $\mathrm{H}_{3} / \mathrm{L}_{3}=4.0$. 
In this work, the geometric optimization of a channel with heated rectangular fins, subjected to forced convection, where the movement of the fluid is generated by the imposition of a pressure difference between the inlet and the outlet of the channel in a steady, two-dimensional, laminar regime, is studied numerically applying the Constructal Design. A Prandtl number of Pr $=0.71$ was considered. The total area of the channel and the area occupied by the two fins were fixed. The problem objective was to maximize the heat transfer between the fins and the fluid. The ratio of height and length of the lower-wall fin, $\mathrm{H}_{3} / \mathrm{L}_{3}$, was varied to find the geometry that best meets the objective, in the range of $0.25 \leq \mathrm{H}_{3} / \mathrm{L}_{3} \leq 4.0$. For this range of $\mathrm{H}_{3} / \mathrm{L}_{3}$ analyzed, three different values of the Bejan number $(\mathrm{Be}=0.182,1.828$ and 18.28) were studied.

It was verified that the imposition of a pressure field results in an effect of the $\mathrm{H}_{3} / \mathrm{L}_{3}$ ratio on (q) opposing to that observed when there is a velocity field imposed on the channel's entrance. It was also noticed that for all simulated Bejan number values, there is always a tendency for the heat transfer rate to decrease with the increase of $\mathrm{H}_{3} / \mathrm{L}_{3}$, with a step drop of q when the height of the fin is the highest possible. Regarding the thermal performance, the results showed that for these simulated cases, a higher Bejan number is ideal. Comparing the geometries that provided the best heat transfer rates, a Bejan number equal to 18.28 has a thermal performance 11.09 times higher than using the lowest value of $(\mathrm{Be})$ simulated. Among the geometries with the same Bejan number, for $\mathrm{Be}=0.182,1.828$ and 18.28 , it was possible to obtain a thermal performance up to $5.05,5.02$ and 1.61 times higher respectively, comparing the best and the worst results for each $(\mathrm{Be})$.

This work showed that the methodology used by the Constructal Design is very useful for the understanding and analysis of problems of channel flows with heat transfer. In future works will be evaluated other Bejan numbers and other geometric ratios for the downstream fin.

\section{REFERENCES}

Azad, A. V., and Amidpour, M., 2011, Economic Optimization of Shell and Tube Heat Excharger Based on Constructal Theory, Energy, Vol. 36, pp. 1087-1096.

Bejan, A., and Lorente, S., 2011, The Constructal Law and the Evolution of Design in Nature, Physics Life Reviews, Vol. 8, pp. 209-240.

Bejan, A., 2000, Shape and Structure, from Engineering to Nature, Cambridge University Press, Cambridge, UK.

Bejan, A., and Lorente, S., 2008, Design with Constructal Theory, Wiley, Hoboken.

Bejan, A., and Zane, J. P., 2012, Design in Nature, New York, Doubleday.

Bejan, A., and Lorente, S., 2013, Constructal
Law of Design and Evolution: Physics, Biology, Technology, and Society, Journal of Applied Physics, Vol. 113, pp. 151301-151301-20.

Bejan, A., 2014, Convection Heat Transfer, John Wiley, Durham, USA.

Fan, Y., and Luo, L., 2008, Recent Applications of Advances in Microchannel Heat Exchangers and Multi-Scale Design Optimisation, Heat Transfer Engineering, Vol. 29, pp. 461-474.

Fluent (version 6.3.16), 2007, ANSYS, Inc.

Kundu, B., and Bhanja, D., 2010, Performance and Optimization Analysis of a Constructal T-Shaped fin Subject to Variable Thermal Conductivity and Convective Heat Transfer Coefficient, International Journal of Heat and Mass Transfer, Vol. 53, pp. 254267.

Lorenzini, G., Biserni, C., Isoldi, L. A., Dos Santos, E. D., and Rocha, L. A. O., 2011a, Constructal Design Applied to the Geometric Optimization of Y Shaped Cavities Embedded in a Conducting Medium, 9 Journal of Electronic Packaging, Vol. 133, pp. 041008-1-041008-8.

Lorenzini, G., Corrêa, R. L., Dos Santos, E. D., and Rocha, L. A. O., 2011b, Constructal Design of Complex Assembly of Fins, ASME Journal of Heat Transfer, Vol. 133, pp. 081902-081909.

Lorenzini, G., Garcia, F. L., Dos Santos, E. D., Biserni, C., and Rocha, L. A. O., 2012, Constructal Design Applied to the Optimization of Complex Geometries: T-Y-Shaped Cavities with Two Additional Lateral Intrusions Cooled by Convection, International Journal of Heat and Mass Transfer, Vol. 55, pp. 1505-1512.

Patankar, S. V., 1980, Numerical Heat Transfer and Fluid Flow, McGraw Hill, New York, USA.

Reis, A. H., 2006, Constructal Theory: from Engineering to Physics and How Flow Systems Develop Shape and Structure, Applied Mechanics Reviews, Vol. 59, pp. 269-282.

Rocha, L. A. O., Lorenzini, E., and Biserni, C., 2005, Geometric Optimization of Shapes on the Basis of Bejan's Constructal Theory, International Communications in Heat and Mass Transfer, Vol. 32, pp. 1281-1288.

Versteeg, H. K., and Malalasekera, W., 2007, An Introduction to Computational Fluid Dynamics The Finite Volume Method, Pearson, England. 